\title{
A novel approach to determining the contribution of the fiber and fines fraction to the water retention value (WRV) of chemical and mechanical pulps
}

\author{
Melanie Mayr (D) Rene Eckhart $\cdot$ Heribert Winter $\cdot$ Wolfgang Bauer
}

Received: 1 December 2016/Accepted: 18 April 2017/Published online: 3 May 2017

(C) The Author(s) 2017. This article is an open access publication

\begin{abstract}
The swelling behavior of pulp fibers has a significant influence on process and product properties. The water uptake of fibers is controlled by a different mechanism. While fiber charge is a driving factor for swelling, the swelling is hindered by the solid structure of the fiber wall. In the case of the fines fraction of pulps, this structure is broken to some extent and the fines are able to swell two to three times more compared to fibers. Thus fines are an important factor regarding the swelling behavior and water retention of pulps, although, at least for chemical pulp, their mass fraction is only between 4 and $15 \%$. For this reason, it is of interest to investigate not just the swelling behavior of pulps, but also of the fiber and fines fractions separately. Swelling is often characterized using the water retention value (WRV) based on a centrifugation technique. WRV measurement is a standardized method for the measurement of the amount of water retained in a given pulp sample. For fine cellulosic materials the standardized procedure cannot be performed. Thus, various modifications of the standard method have been applied by different groups for the evaluation of these materials. Due to
\end{abstract}

M. Mayr $(\varangle) \cdot$ R. Eckhart · W. Bauer

Institute of Paper, Pulp and Fiber Technology, Graz

University of Technology, $8010 \mathrm{Graz}$, Austria

e-mail: melanie.mayr@tugraz.at

H. Winter

Sappi Paper Holding, 8101 Gratkorn, Austria these modifications the values obtained cannot be related to the standardized method. In this work a novel approach to determining the WRV of the fines fraction in a given pulp based on the standard procedure will be presented. This allows a quantitative investigation of the contribution of the fibers and fines fraction to the WRV of any given pulp sample.

Keywords Water retention value $\cdot$ Swelling . Fibers $\cdot$ Fines $\cdot$ Refining

\section{Introduction}

The swelling tendencies of pulps have an important impact on sheet consolidation and interfiber bonding. (Chen et al. 2013; Hii et al. 2012; Koskenhely et al. 2005). As swelling is influenced by structural changes and pulp chemistry, the effect of different pulp treatments can be monitored by its characterization and thus swelling yields important information regarding, e.g., dewaterability on the paper machine or strength development after sheet consolidation. The swelling behavior influenced by the pulping process and yield (Andreasson et al. 2003; Forsstrom et al. 2005; Stone and Scallan 1967), by drying and rewetting (Stone et al. 1968; Wang 2006) and by refining (Bäckström and Haimnar 2010; Laivins and Scallan 1996) have been documented. Further, swelling is influenced by enzymatic treatment (Gil et al. 2009; Stock et al. 1995), by chemical modification 
(Chen et al. 2013; Racz and Borsa 1997; Scallan 1983; Zhao et al. 2016) or by addition of cationic polymers (Aarne et al. 2012; Strom and Kunnas 1991). Swelling depends to a certain extent, also, on charge density. The more carboxylic groups, the higher the swelling potential. The effect of anionic groups can be explained based on the Donnan theory (Rasanen et al. 2001; Scallan 1983). The anionic groups located in the cell are balanced by positively charged counterions. If there are more ions in the fiber wall than in the surrounding liquid, an osmotic pressure difference arises. This pressure difference is balanced by the fiber wall absorbing water and thus 'diluting" the charges within the fiber wall. Based on this fundamental effect it is obvious that a change in swelling can result from $\mathrm{pH}$, conductivity of the water phase, the types of counterions of the carboxylic groups and addition of chemical additives (Scallan 1983; Scallan and Grignon 1979; Stone et al. 1968; Strom and Kunnas 1991). The final degree of swelling of a pulp fiber is limited by the structure of the fiber wall, which hinders the unlimited dilatation of the fiber. Stone and Scallan (1967), therefore, defined different regions of a fiber, whose water holding capacity obviously is affected by the fiber morphology. The accessible volume and therefore the water holding capacity of these regions change due to chemical, mechanical or thermal action.

Several methods for the measurement of swelling and related properties are reported in the literature. These include water evaporation (Stone and Scallan 1967), thermoporosity measurement (Wang et al. 2003), nuclear magnetic resonance (NMR) (Forsstrom et al. 2005; Hui et al. 2009; Maloney et al. 1997) and inverse size exclusion chromatography (ISEC) (Berthold and Salmén 1997). The two most common methods, however, are the fiber saturation point (FSP) and the water retention value (WRV).

In FSP measurement, a weighed quantity of wet pulp of known moisture content is immersed in a dilute aqueous solution of a high molecular weight dextran polymer (approximately $1 \mathrm{wt} \%$ in water). The polymer molecules are larger in size than the pores and therefore cannot enter the cell wall. Thus water contained in the pores will lead to a change in the polymer concentration. The FSP, which can be seen as the amount of water in the cell wall, is then determined based on Stone and Scallan (1967). As swelling also depends on the surrounding liquid, it is advantageous that this measurement is performed in aqueous solution, without any structural changes to the fibers, which are constantly in a wet state. Thus it is considered the most direct measurement of fiber swelling (Maloney et al. 1999). Nevertheless, a high measurement uncertainty compared to other methods has to be accepted, as changes in polymer concentrations are quite small. The accessibility of dextran to the fiber lumen might also depend on the fiber damage. Dextran molecules may have difficulties approaching a fiber when its surface is highly fibrillated and water entrapped between these fibrils and the fiber surface could then be considered as inaccessible (Stone et al. 1968).

WRV measurement has a quite different principle. The WRV is a centrifugation technique, determining the water retained in a fiber pad after the application of centrifugal forces under defined conditions. It is an indirect method influenced by sample mass, centrifugation force and time, and therefore has to be performed under defined conditions specified by the standard (ISO 23714:2014). Nevertheless, a good correlation of FSP and WRV for different types of pulps was observed up to certain values (Scallan and Carles 1972), after which the WRV fell below the FSP. To reach this level of swelling the fibers have to be highly fibrillated. It was assumed that the more swollen a fiber is, the more sensitive it will be against compression, forcing out the water during centrifugation (Scallan and Carles 1972). On the other hand, one might argue that the FSP obtains higher values, as water molecules trapped between highly swollen fibrils and the fiber surface become inaccessible as mentioned before (Stone et al. 1968). In another study it was shown that WRV also differs from FSP for less swollen pulps. It was concluded that water retained between the fibers and water removed from the cell wall in centrifugation are responsible for these differences (Maloney et al. 1999). The influence of drying and rewetting on swelling was found to be higher for WRV than for FSP (Forsstrom et al. 2005), and the correlation of WRV and FSP is affected by different refining strategies for various types of pulps (Hui et al. 2009). It can be concluded that measurement of pulp fiber swelling is not a straightforward task and that the method, as well as the morphology and origin of the pulp sample, have to be considered. Depending on the method used, different aspects of swelling are evaluated. 
As mentioned before, both charge and structural properties of fibers affect swelling. For example, carboxymethylation of unbleached hardwood kraft pulp (UBHK) leading to a $280 \mu \mathrm{eq} / \mathrm{g}$ higher total fiber charge resulted in an increased WRV of $1.4 \mathrm{~g}$ water per $\mathrm{g}$ fiber (Chen et al. 2013), while the fiber morphology remained almost unchanged. Refining, on the other hand, has little effect on the fiber total charge (Horvath and Lindström 2007), but generates fines (particles passing a 200 mesh screen), or more precisely, secondary fines (Krogerus et al. 2002). Primary and secondary fines are usually both present in a refined pulp. Bäckström et al. (2008) removed primary fines prior to refining and found differences in WRV between unbleached kraft secondary fines and the corresponding fibers to be $4.2 \mathrm{~g}$ water per $\mathrm{g}$ fiber. As secondary fines are parts of the fiber wall torn out by the refining treatment, this change in swelling can be assumed to be mainly caused by structural changes. Several other studies also reported that fines after refining, which include primary and secondary fines, swell two to three times more than fibers, i.e. fines hold up to three times more water than fibers (Laivins and Scallan 1996). Although there are these obvious differences, the impact of the swelling of fines on paper properties was rarely discussed. Fines were often neglected from such investigations, because it is a tedious task using the common methods to separate fines in a high enough quantity to measure swelling. Swelling of fines can be determined by the FSP method directly, but a high amount of fines is required and the FSP method is also quite a time consuming procedure. For WRV measurement, a fiber pad first needs to be formed by filtration, which is not practicable in the case of the high dewatering resistance of fines. Thus several modifications of the method were made to be able to measure the WRV of pulp fines or other fine cellulosic materials. The mass of the sample was reduced in almost all modifications, centrifugation was replaced by other methods to remove excess water, membranes were implemented to be able to hold back the fine material and centrifugation time and force were varied. It was shown that each of these modifications had an influence on the results (Cheng et al. 2010; Scallan and Carles 1972). Due to these modifications the values obtained for the fines fraction cannot be related to the standardized method anymore, and the contribution of fibers and the corresponding fines fraction on the WRV of a given pulp sample cannot be directly determined. An approach to measure the WRV of micro and nanofibrillated fine fractions on the basis of the standard procedure was presented by Rantanen et al. (2015). With this method, however, only the WRV of the fines fraction can be determined, neglecting the WRV of the fiber fraction, which would be important for papermaking pulps. In this work a novel approach to determining the WRV of the fiber and the fines fraction based on the standard procedure is presented.

\section{Materials and methods}

Pulp samples and sample preparation

In this study various industrial chemical and mechanical pulp samples from different process steps (bleaching, refining) were chosen for the validation of the novel approach (see Table 1). The gravimetric fines content of these pulps was determined by the Britt Dynamic Drainage Jar method (BDDJ, SCAN-CM 66:05). The WRV of these pulps was determined according to the standard method (ISO 23714:2014). A fiber pad formed by filtration has to have a dry mass of the pad of $2.5 \mathrm{~g}$. This fiber pad was centrifuged (centrifugation time: $30 \mathrm{~min}$, centrifugation force: $3000 \mathrm{~g}$ ) and the pad was weighed after centrifugation $\left(m_{\text {wet }}\right)$, dried and weighed again $\left(m_{\text {dry }}\right)$. The water retention value is calculated according to Eq. 1 .

Table 1 List of pulps and treatments

\begin{tabular}{lll}
\hline Nr. & Pulp & Treatment \\
\hline P1 & Pressurized ground wood 1 & Unbleached \\
P2 & Pressurized ground wood 1 & Bleached \\
P3 & Softwood kraft pulp 1 & Unbleached, unrefined \\
P4 & Softwood kraft pulp 2 & Unbleached, unrefined \\
P5 & Softwood kraft pulp 2 & Bleached, unrefined \\
P6 & Softwood kraft pulp 3 & Bleached, unrefined \\
P7 & Softwood kraft pulp 3 & Bleached, refined \\
P8 & Hardwood kraft pulp 1 & Bleached, unrefined \\
P9 & Hardwood kraft pulp 1 & Bleached, refined \\
P10 & Softwood sulfite pulp 1 & Unbleached, unrefined \\
P11 & Softwood sulfite pulp 1 & Bleached, unrefined \\
P12 & Softwood sulfite pulp 1 & Bleached, refined \\
\hline
\end{tabular}


$\mathrm{WRV}\left[\frac{\mathrm{g}}{\mathrm{g}}\right]=\frac{m_{\mathrm{wet}}}{m_{\mathrm{dry}}}-1$

In order to obtain a sufficient amount of the fines fraction and a pure fiber fraction, the pulps were fractionated at $1 \%$ solids content using a laboratoryscale pressure screen. The pressure screen was equipped with a perforated plate (hole diameter $100 \mu \mathrm{m}$ ). The material passing through this plate was defined as the fines fraction. The pulp was recirculated through the pressure screen until the remaining volumetric fines content measured with a commercial flow cell based fiber analyzer $\left(\mathrm{L} \& \mathrm{~W}\right.$ Fibertester ${ }^{+}$) was lower than $0.5 \%$. This pulp fraction was defined as the fiber fraction.

Determination of WRV by the novel method

The fiber and fines fractions obtained using the abovementioned screening procedure were recombined to obtain three blends per pulp sample containing proportions of fines between 5 and $15 \%$ for chemical pulps and between 15 and $30 \%$ for mechanical pulps. The WRV of all these blends was determined in duplicate according to the standard (ISO 23714:2014).

Each component (fibers and fines) is considered to have an intrinsic water retention capacity. Based on the knowledge that fines show a higher WRV than the fibers, it is expected that WRV increases linearly when the fines content is increased, as depicted in Fig. 1.

The linear equation (Eq. 2) obtained from this relation was solved according to the two boundary conditions $\mathrm{w}_{\text {Fines }}=0 \%(100 \%$ fibers $)$ and $\mathrm{w}_{\text {Fines }}=100 \%$ to

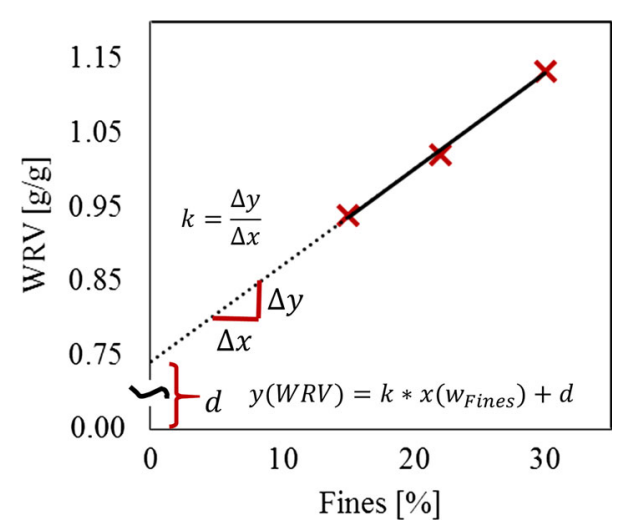

Fig. 1 Linear development of WRV of pulp blends in dependency of the fines content of these blends determine the WRV of fibers (WRVFiber, Eq. 3) and the WRV of fines (WRVFines, Eq. 4), respectively. $\mathrm{WRV}_{\text {Pulp }}$ was calculated using Eq. 5 based on the values for $\mathrm{WRV}_{\text {Fines }}, \mathrm{WRV}_{\text {Fiber }}$ and the gravimetric fines content ( $\mathrm{W}_{\text {Fines }}$, see Table 1) measured for the original pulp. The contribution of fibers and fines to $\mathrm{WRV}_{\text {Pulp }}$ was also determined by this approach .

$$
\begin{aligned}
\mathrm{WRV} & =k * w_{\text {Fines }}[\%]+d \\
w_{\text {Fines }} & =0 \% \rightarrow \mathrm{WRV}=d \triangleq \mathrm{WRV}_{\text {Fiber }} \\
w_{\text {Fines }} & =100 \% \rightarrow \mathrm{WRV}_{\text {Pulp }} \\
& =k * 100+d \triangleq \mathrm{WRV}_{\text {Fines }}
\end{aligned}
$$

$\mathrm{WRV}_{\text {Pulp }}=\mathrm{WRV}_{\text {Fiber }} *\left(1-w_{\text {fines }}\right)+\mathrm{WRV}_{\text {Fines }} * w_{\text {fines }}$

\section{Results}

Validation of the novel approach

For the validation of the novel approach, the WRV of the pulps were measured directly by the standard method and additionally calculated according to Eq. 5 using the approach described above (see Table 2). To allow a comparison of calculated and measured WRV values, it is of importance that the fine fraction obtained by pressure screening is similar to the fine fraction obtained with a BDDJ (SCAN-CM 66:05). Size distributions of the fraction generated by the pressure screen and the fraction generated with the BDDJ, show a similar size range (see "Appendix"). Thus, similar fractions are obtained by both methods, allowing the determination of $\mathrm{WRV}_{\text {Pulp }}$ based on the fines content obtained by the BDDJ method.

The values obtained by the calculation were correlated with the measured values of the pulps (see Fig. 2). A coefficient of determination $R^{2}$ of 0.985 demonstrated the validity of the novel approach.

The WRV is not only a material property, but also depends on structural properties (structure of the pad, Maloney et al. 1999). The influence of structural properties becomes evident as the values for pure fibers $\left(\mathrm{WRV}_{\text {Fiber }}\right)$ measured directly were higher compared to the calculated ones, applying the novel approach (Table 2). The difference was even higher for unrefined pulp samples than for refined pulp (Table 2). As 
Table 2 Gravimetric fines content (SCAN-CM 66:05) of pulp samples (see Table 1) and WRV (ISO 23714:2014) measured directly from these pulps

\begin{tabular}{|c|c|c|c|c|c|c|}
\hline \multirow[t]{2}{*}{ Nr. } & \multirow[t]{2}{*}{ Fines content $(\%)$} & \multicolumn{2}{|c|}{ WRV (g/g) standard } & \multicolumn{3}{|c|}{ WRV (g/g) novel approach (calculated values Eqs. 3-5) } \\
\hline & & Fiber & Pulp (measured) & Fiber & Fines & Pulp \\
\hline $\mathrm{P} 1$ & 33.1 & 0.825 & 1.202 & 0.755 & 2.045 & 1.182 \\
\hline $\mathrm{P} 2$ & 33.5 & 0.824 & 1.139 & 0.741 & 2.041 & 1.176 \\
\hline P3 & 2.7 & 1.275 & 1.276 & 1.203 & 3.233 & 1.257 \\
\hline P4 & 3.4 & 1.124 & 1.160 & 1.119 & 2.489 & 1.166 \\
\hline P5 & 4.3 & 1.090 & 1.083 & 1.035 & 2.585 & 1.101 \\
\hline P6 & 4.9 & 0.805 & 0.812 & 0.734 & 2.754 & 0.832 \\
\hline P7 & 7.7 & 1.061 & 1.226 & 1.046 & 3.366 & 1.224 \\
\hline P8 & 9.8 & 0.812 & 0.877 & 0.738 & 2.138 & 0.874 \\
\hline P9 & 10.8 & 0.924 & 1.099 & 0.896 & 2.666 & 1.086 \\
\hline P10 & 4.8 & 1.219 & 1.184 & 1.172 & 2.242 & 1.223 \\
\hline P11 & 4.4 & 1.103 & 1.086 & 1.048 & 2.348 & 1.105 \\
\hline P12 & 11.5 & 1.178 & 1.324 & 1.154 & 2.914 & 1.357 \\
\hline
\end{tabular}

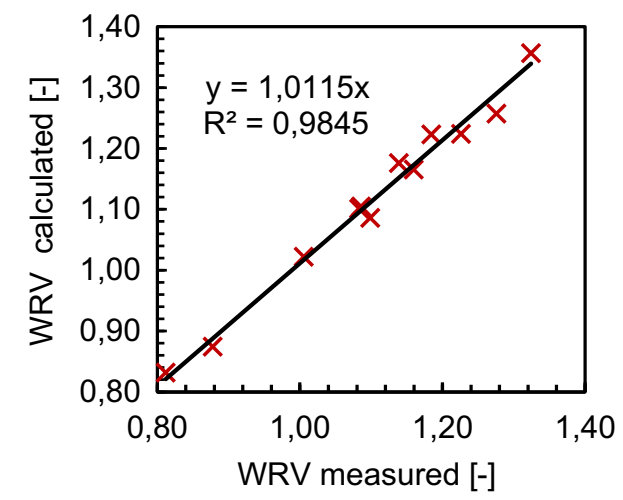

Fig. 2 WRV of pulps given in Table 2; Correlation between values measured directly using the standard procedure $(x$-axis) and calculated values (Eq. 5) based on the novel approach ( $y$ axis)

an example for a mechanical pulp (P2) as well as for a chemical pulp (P5), WRV values measured for blends with different fines content and for the pure fiber fraction are presented in Fig. 3, illustrating the deviation of $\mathrm{WRV}_{\text {Fiber }}$ from the linear relationship between fines content and WRV. This behavior might be explained by structural changes of the pulp pad due to capillary forces introduced by fines and external fibrils of fibers. Capillary forces lead to a higher densification of the pad similar to the effect fines have on sheet consolidation (Sirviö and Nurminen 2004). This structural impact may also be present when the novel approach is used based on blends with different fines contents, but at least it follows a linear trend.
In the validation trials presented above, fibers were always mixed with the originally corresponding fines fraction. To validate the stability and structural impact of different fiber and fines morphology on WRV applying the novel approach, the fiber and fines fractions of two morphologically and chemically different pulps, pressurized groundwood (PGW, Table 2-P1) and unbleached softwood kraft (UBSK, Table 2-P3), were recombined. UBSK fibers and PGW fibers were combined with three levels of their own fines again (Trial A and Trial B), as there was a certain time period, between the above discussed validation (Table 2) and this experiment, possibly leading to changes in pulp quality. USBK fibers were additionally combined with three levels of PGW fines (Trial C) and vice versa (PGW fibers with UBSK fines (Trial D)). $\mathrm{WRV}_{\text {Fiber }}$ and $\mathrm{WRV}_{\text {Fines }}$ were determined for all four trials using Eqs. 3, 4 and are listed in Table 3. $\mathrm{WRV}_{\text {Fiber }}$ obtained by mixing the fibers with the corresponding fines and by mixing it with fines from the other pulp led to similar results. For $\mathrm{WRV}_{\text {Fines }}$ the differences were slightly larger, presumably because of greater differences in fines morphology influencing the water removal during centrifugation. Still, the variations in the WRV results are within the measurement uncertainty given in the standard. Thus, the novel approach is also applicable in determining $\mathrm{WRV}_{\text {Fiber }}$ or $W R V_{\text {Fines }}$ without the necessity for the fiber and the fines fraction to come from the same original pulp. This approach could also be useful in the 
Fig. 3 WRV values for mechanical pulp (P2) and chemical pulp (P5), measured for blends with different fines content and for the pure fiber fraction $(x)$ and $\mathrm{WRV}_{\text {Fiber }}$ calculated by the novel approach (o)

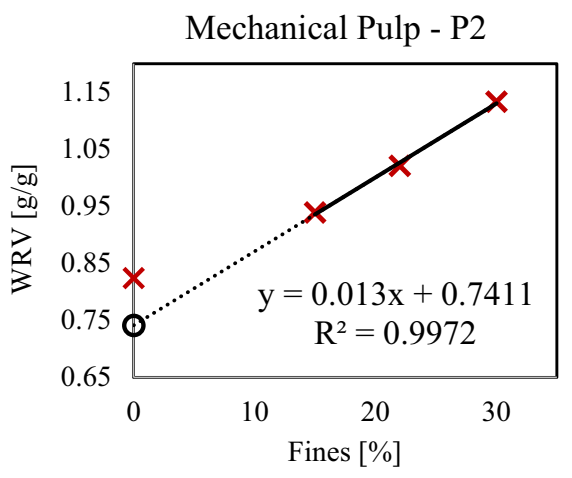

Table 3 Determination of WRV fibers and fines from UBSK and PGW pulps. Determination for fiber and corresponding fines fraction (A, B) and for combinations of different pulp fibers and fines $(C, D)$

\begin{tabular}{|c|c|c|c|c|}
\hline \multirow[t]{3}{*}{ Trial } & \multicolumn{4}{|c|}{ WRV (g/g) } \\
\hline & \multicolumn{2}{|c|}{ UBSK } & \multicolumn{2}{|l|}{ PGW } \\
\hline & Fiber & Fines & Fiber & Fines \\
\hline A & 1.26 & 3.16 & & \\
\hline B & & & 0.76 & 1.75 \\
\hline $\mathrm{C}$ & 1.24 & & & 1.55 \\
\hline $\mathrm{D}$ & & 3.46 & 0.80 & \\
\hline
\end{tabular}

determination of the WRV of other cellulosic fine materials, such as micro- or nanofibrillated celluloses.

\section{Application example}

To underline the value of this novel method, we present an exemplary application regarding the development of WRV with refining. The unrefined bleached softwood kraft pulp (BSK) (Table 2-P5) was refined using an industrial, single disk refiner and the corresponding refined BSK pulp (Table 2-P6) was obtained. Table 4 lists the mass fractions for fibers, primary and secondary fines of the unrefined and refined BSK pulp. Unrefined pulp consists only of fibers and primary fines. The percentage of primary fines is assumed to remain constant after refining, and all additionally created fines during refining are classified as secondary fines and assumed to originate only from the fibers. Thus the amount of fibers decreases and the total amount of fines increases after refining, while the amount of primary fines remains constant.

In Fig. 4a the WRV of the unrefined and refined BSK fibers $\left(W R V_{\text {Fiber }}\right)$ and fines $\left(W R V_{\text {Fines }}\right)$ is shown. With refining, $\mathrm{WRV}_{\text {Fiber }}$ increases due to internal and
Table 4 Mass fractions of components present in unrefined and refined BSK pulp

\begin{tabular}{lll}
\hline & \multicolumn{2}{l}{ Mass fractions (\%) } \\
\cline { 2 - 3 } & BSK (unrefined) & BSK (refined) \\
\hline Fiber & 95.1 & 92.3 \\
Primary fines & 4.9 & 4.9 \\
Secondary fines & 0.0 & 2.8 \\
\hline
\end{tabular}

external fibrillation of the fibers. $W R V_{\text {Fines }}$ increases because of the production of secondary fines, which usually swell more than primary fines (Bäckström et al. 2008). In Fig. $3 b$ the mass fractions of fibers and fines contained in the pulp are also taken into account (see Eq. 5) and show $\mathrm{WRV}_{\text {Pulp }}$, including the contribution

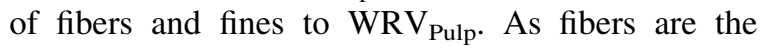
dominant mass fraction in unrefined and refined BSK pulp, $\mathrm{WRV}_{\text {Fiber }}$ is the major contributor to $\mathrm{WRV}_{\text {Pulp. }}$. Yet despite their low mass fraction, fines have quite a significant influence on $\mathrm{WRV}_{\text {Pulp }}$ because of their much higher WRV. With refining, the contribution of
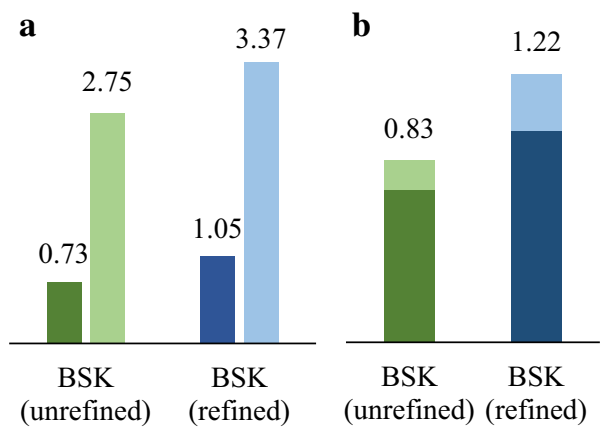

Fig. 4 a $\mathrm{WRV}_{\text {Fiber }}$ (dark bars) and $\mathrm{WRV}_{\text {Fines }}$ (light bars) of unrefined and refined BSK pulp; $\mathbf{b} \mathrm{WRV}_{\text {Pulp }}$ of unrefined and refined BSK pulp and the contribution of fibers (dark bars) and fines (light bars) calculated according to Eq. 5 


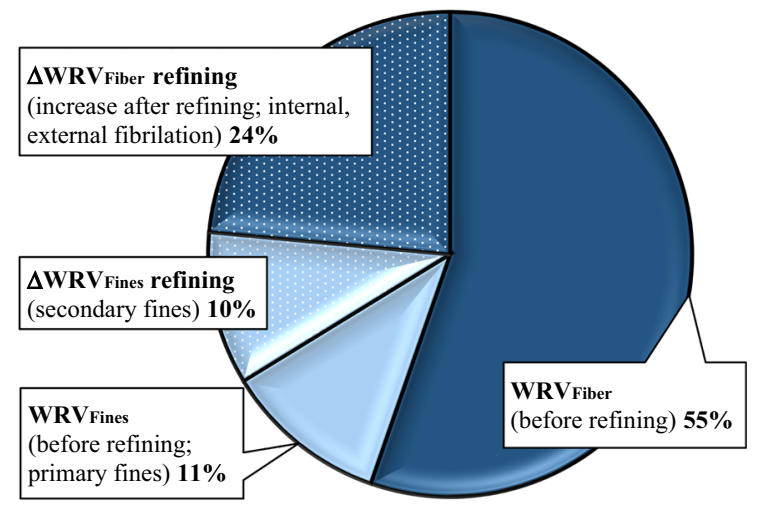

Fig. 5 Contribution of fibers (dark areas, 79\%) and fines (light areas, $21 \%$ ) to the WRV of refined BSK pulp and increase of WRV of fibers (dotted dark area, 24\%) and WRV of fines (dotted light area, 10\%) due to refining

the fines fraction increases, not only due to an increase of $\mathrm{WRV}_{\text {Fines }}$ (Fig. 4a), but also by the higher mass fraction of fines after refining (Table 4). In the refined BSK pulp the fibers contribute $79 \%$ and the fines of

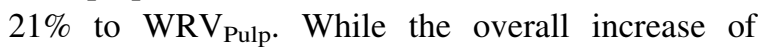
$\mathrm{WRV}_{\text {Pulp }}$ due to refining can of course be determined using the standard WRV method, the novel method provides additional information by distinguishing the effect refining has on fibers and fines (see Fig. 5). For the example of the BSK pulp, refining increased the WRV of fibers as a result of internal and external fibrillation by $24 \%$ and the WRV of the fines by $10 \%$ by the production of secondary fines.

\section{Conclusion}

Nearly all processes in pulping and stock preparation, such as bleaching, drying or refining, influence the amount of water retained in a pulp measured by the WRV. The simple method presented allows separate determination of the WRV of pulp fibers and fines. The contribution of fibers and fines to the water holding behavior of a given pulp can thus be calculated using the standardized WRV measurement procedure. This is seen as an advantage over alternative methods to determine the WRV of cellulosic fines, which require modifications to the standard procedure and therefore are not directly comparable. $\mathrm{WRV}_{\text {Pulp }}$ derived from the novel approach is comparable to values measured by the standardized procedure, which underlines the validity of the method.

As it is not necessary to blend fibers and fines from the same origin to obtain values for the contribution of fibers and fines to the WRV, this method might also be useful in the determination of the WRV contribution of other cellulosic fine materials, such as MFC or NFC.

The example of the development of WRV with refining underlines the value of the novel approach. While the overall increase of the WRV of a pulp can be measured using the standardized procedure, the novel approach, in addition, allows us to differentiate between $\mathrm{WRV}_{\text {Fiber }}$ and $\mathrm{WRV}_{\text {Fines, }}$ and thus the contribution of each fraction to the water holding behavior. This valuable information allows a more targeted process and product optimization.

Acknowledgments Open access funding provided by Graz University of Technology. The authors acknowledge the industrial partners Sappi Gratkorn, Zellstoff Pöls, Norske Skog Bruck and Mondi Frantschach, the Austrian Research Promotion Agency (FFG), COMET, BMVIT, BMWFJ, the Province of Styria and Carinthia for their financial support of the K-project FLIPPR ${ }^{\circ}$.

Open Access This article is distributed under the terms of the Creative Commons Attribution 4.0 International License (http:// creativecommons.org/licenses/by/4.0/), which permits unrestricted use, distribution, and reproduction in any medium, provided you give appropriate credit to the original author(s) and the source, provide a link to the Creative Commons license, and indicate if changes were made.

\section{Appendix}

Comparison of BDDJ and pressure screen

See Fig. 6.

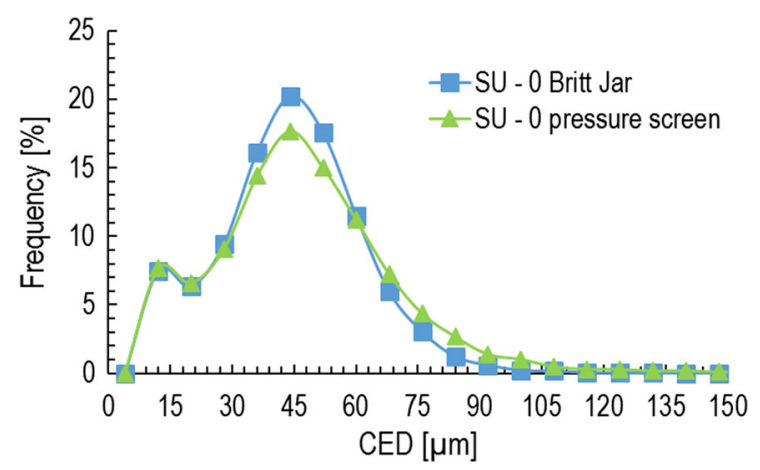

Fig. 6 Size distributions (Fibertester ${ }^{+}$) of the fines fraction of bleached unrefined softwood sulfite pulp $1(\mathrm{SU}-0)$ fractionated with the Britt Jar method (hole diameter $76 \mu \mathrm{m}$ ) and with a lab-scale pressure screen (hole diameter $100 \mu \mathrm{m}$ ) 


\section{References}

Aarne N, Kontturi E, Laine J (2012) Carboxymethyl cellulose on a fiber substrate: the interactions with cationic polyelectrolytes. Cellulose 19(6):2217-2231

Andreasson B, Forsström J, Wågberg L (2003) The porous structure of pulp fibres with different yields and its influence on paper strength. Cellulose 10(2):111-123

Bäckström M, Haimnar LA (2010) The influence of the counterions to the charged groups on the refinability of never-dried bleached pulps. BioResources 5(4):2751-2764

Bäckström M, Kolar MC, Htun M (2008) Characterisation of fines from unbleached kraft pulps and their impact on sheet properties. Holzforschung 62(5):546-552

Berthold J, Salmén L (1997) Inverse size exclusion chromatography (ISEC) for determining the relative pore size distribution of wood pulps. Holzforschung 51(4):361-368

Chen Y et al (2013) Fiber properties of eucalyptus kraft pulp with different carboxyl group contents. Cellulose 20(6):2839-2846

Cheng Q et al (2010) Water retention value measurements of cellulosic materials using a centrifuge technique. BioResources 5(3):1945-1954

Forsstrom J, Andreasson B, Wagberg L (2005) Influence of pore structure and water retaining ability of fibres on the strength of papers from unbleached kraft fibres. Nord Pulp Pap Res J 20(2):176-185

Gil N et al (2009) Use of enzymes to improve the refining of a bleached Eucalyptus globulus kraft pulp. Biochem Eng J 46:89-95

Hii C et al (2012) The effect of MFC on the pressability and paper properties of TMP and GCC based sheets. Nord Pulp Pap Res J 27(2):388-396

Horvath A, Lindström T (2007) Indirect polyelectrolyte titration of cellulosic fibers-surface and bulk charges of cellulosic fibers. Nord Pulp Pap Res J 22(1):087-092

Hui L, Liu Z, Ni Y (2009) Characterization of high-yield pulp (HYP) by the solute exclusion technique. Bioresour Technol 100(24):6630-6634

Koskenhely K et al (2005) Effect of refining intensity on pressure screen fractionated softwood kraft. Nord Pulp Pap Res J 20(2):169-175

Krogerus B, Fagerholm K, Tiikkaja E (2002) Fines from different pulps compared by image analysis. Nord Pulp Pap Res J 17(4):440-444
Laivins GV, Scallan AM (1996) The influence of drying and beating o the swelling of fines. J Pulp Pap Sci 22:178

Maloney TC, Li TQ, Weise U, Paulapuro H (1997) Intra- and inter-fibre pore closure in wet pressing. Appita J 50(4):301-306

Maloney TC, Laine JE, Paulapuro H (1999) Comments on the measurement of cell wall water. Tappi J 82(9):125-127

Racz I, Borsa J (1997) Swelling of carboxymethylated cellulose fibres. Cellulose 4(4):293-303

Rantanen J, Dimic-Misic K, Kuusisto J, Maloney TC (2015) The effect of micro and nanofibrillated cellulose water uptake on high filler content composite paper properties and furnish dewatering. Cellulose 22(6):4003-4015

Rasanen E, Stenius P, Tervola P (2001) Model describing Donnan equilibrium, $\mathrm{pH}$ and complexation equilibria in fibre suspensions. Nord Pulp Pap Res J 16(2):130-139

Scallan A (1983) The effect of acidic groups on the swelling of pulps: a review. Tappi J 66(11):73-75

Scallan AM, Carles JE (1972) The correlation of the water retention value with the fibre saturation point. Sven Papperstidning 75(17):699-703

Scallan AM, Grignon J (1979) The effect of cations on pulp and paper properties. Sven Papperstidning 82(2):40-47

Sirviö J, Nurminen I (2004) Systematic changes in paper properties caused by fines. Pulp Pap Can 105(8):193-196

Stock $\mathrm{G}$ et al (1995) Upgrading recycled pulps using enzymatic treatment. Tappi J 78(2):79

Stone JE, Scallan AM (1967) The effect of component removal upon the porous structure of the cell wall of wood. II. Swelling in water and the fiber saturation point. Tappi J 50(10):496-501

Stone JE, Scallan AM, Abrahamson B (1968) Influence of beating on cell wall swelling and internal fibrillation. Sven Papperstidning 19(10):687-694

Strom G, Kunnas A (1991) The effect of cationic polymers on the water retention. Nord Pulp Pap Res J 11(1):12-19

Wang X (2006) Improving the papermaking properties of kraft pulp by controlling hornification and internal fibrillation. Helsinki University of Technology, Finland

Wang X, Maloney TC, Paulapuro H (2003) Internal fibrillation of never dried and once dried pulp. Appita 56(6):455-459

Zhao C et al (2016) Enhancing the inter-fiber bonding properties of cellulosic fibers by increasing different fiber charges. Cellulose 23(3):1617-1628 